\title{
Experimental Study on Slope Deformation Monitoring Based on a Combined Optical Fiber Transducer
}

\author{
Yong Zheng, ${ }^{1,2}$ Dong-Yan Liu, ${ }^{1,2}$ Zheng-Wei Zhu, ${ }^{1,2}$ Hong-Lin Liu, ${ }^{1,2}$ and Bang Liu ${ }^{3}$ \\ ${ }^{1}$ School of Civil Engineering of Chongqing University, Chongqing 400045, China \\ ${ }^{2}$ Key Laboratory of New Technology for Construction of Cities in Mountain Area, Chongqing University, \\ Ministry of Education, Chongqing 400045, China \\ ${ }^{3}$ College of Electro-Optic Engineering of Chongqing University, Chongqing 400044, China
}

Correspondence should be addressed to Zheng-Wei Zhu; zqiao99@126.com

Received 20 November 2016; Revised 16 February 2017; Accepted 26 February 2017; Published 16 March 2017

Academic Editor: Carlos Ruiz

Copyright (C) 2017 Yong Zheng et al. This is an open access article distributed under the Creative Commons Attribution License, which permits unrestricted use, distribution, and reproduction in any medium, provided the original work is properly cited.

Landslide monitoring is very important in predicting the behavior of landslides, thereby ensuring environment, life, and property safety. On the basis of our previous studies, a novel combined optic fiber transducer (COFT) for landslides monitoring and the related analysis methods are presented. Based on the principles of optical fiber microbending loss, the empirical formula of the shearing displacement of sliding body versus optical loss was established through a stretching test of optical fiber bowknot. Then the COFT grouting direct shearing tests, a large-scale landslide model test, and numerical modeling verification with FLAC ${ }^{3 \mathrm{D}}$ are carried out. According to the results, the initial measurement precision of the designed COFT in sandy clay is $1 \mathrm{~mm}$; its monitoring sliding distance is larger than $26.5 \mathrm{~mm}$. The calculated values based on empirical formula are in good agreement with the laboratory tests and numerical simulation results. When the ratio of cement and sand in mortar is 1:5, the error between the calculated displacement and the measured displacement of sliding surface is the smallest. The COFT with expandable polystyrene (EPS) as its base material performs better in monitoring sandy clay slopes because both the error and the mean square deviation of the empirical formula are smaller.

\section{Introduction}

In China, geological disasters are not rare. Among those disasters, landslides are the geological disasters with the broadest range, the most serious damage, and the longest duration for human beings. According to statistics of the Chinese Institute of Geological Environment Monitoring [1], during the 10 years from 2006 to 2016, China has suffered a loss of 45.556 billion Yuan and 11,230 casualties due to such geological disasters as landslides. However, the successful forecasting rate is only $3.76 \%$. This is mainly because it is hard for people to forecast the time, location, scope, and scale of landslides; therefore, it is even harder to take active measures. Thus, it is important for us to successfully forecast its occurrence time, scope, and location at an early stage and acquire the early, remote, real-time monitoring on the landslides.

As to displacement monitoring, methods are divided into surface base [2] and inner depth based. The latter methods are mainly as follows: inclinometer [3] is relatively accurate, but the real-time performance and the telemetry effect are poor. Time domain reflectometer (TDR) [4], based on a coaxial cable, can realize real-time telemetry at a lowest cost, with shortest data acquisition time and higher safety. However, the initial accuracy is poor, and measurement range is not large. Fiber Bragg grating (FBG) [5-7] has the advantages of high measuring precision, strong instantaneity, a wide measuring range, and antielectromagnetic interference, but the price is so dear. Brillouin Optical Time Domain Analysis (BOTDA) $[8,9]$ has a strong light signal and can realize real-time distributed monitoring. But since BOTDA needs incident laser from both ends of the optical fiber, it makes monitoring inconvenient. The monitoring system is costly and cannot measure the breakpoint. Although all of these can acquire early warning parameters, according to the monitoring data, it is hard to achieve such advantages as the identification of the sliding direction, high initial measurement accuracy, 
a large measuring range, a low paving price, and remote and real-time monitoring at the same time. Therefore, based on optical fiber sensing principles, optical time domain reflectometry (OTDR) [10-12], and using the spatial structure of the beam, a new optical fiber sensor for landslides monitoring, COFT, was invented. This transducer has obtained a Chinese patent [13]. The fourth generation of the transducer has been invented, with improvements being made to the transducer and the effects of different mortar strength, different types, and dimensions of base materials on the performance of the transducer were studied [14, 15]. These studies verify that the transducer has a relatively high initial measurement accuracy, a large measuring range, cheap paving, and the ability to determine the landslide direction and can realize real-time, remote monitoring.

However, before this, the empirical formulas based on COFT had not been studied, which restricted the application of this transducer in field monitoring. In this paper, an empirical formula based on COFT related to the value of optical fiber loss and the shearing displacement of sliding body is established through the tensile test of microbending loss of optical fiber bowknot, direct shearing tests of grouting pieces, and the operating mechanism of the COFT; the feasibility and reliability of the empirical formula for landslide monitoring are verified through numerical modeling and landslide model test.

\section{Slope Monitoring Technology Based on COFT}

2.1. Principles of Optical Fiber Microbending Loss. Macrobending loss and microbending loss are caused when optical fiber is bent, and microbending loss can be measured by using optical time domain reflectometer (OTDR) based on which a sensor can be designed to monitor the strain. Theoretically, the relationship between microbending loss of the optical fiber $\left(\partial_{b}\right)$ and its curvature radius $(\rho)$ can be expressed as the following $[15,16]$ :

$$
\partial_{b}=C_{1} e^{-C_{2} \rho},
$$

where $C_{1}$ and $C_{2}$ are constant to be confirmed. According to formula (1), microbending loss is inversely proportional to the exponential function of its curvature radius. This means that the decrease in the curvature radius will cause an approximately exponential increase in microbending loss. Therefore, the sensitivity of the sensor will be very high as long as the microbending modulation mechanism is designed reasonably.

This is exactly the feature of optical fiber that is used by the COFT in slope monitoring technology, which designs a bowknot as the microbending modulation mechanism, as shown in Figure 1. When the movement of the optical fiber reduces the width of the bowknot, it will thus reduce the curvature radius of the bowknot and cause microbending loss, which will be captured by OTDR. The COFT, which is used to monitor the deep displacement of the slope, mainly consists of base materials, capillary tubes, and optical fiber. Capillary tubes which can shrink moving up and down were placed at the center of the base material and around tube, one strand of optical fiber was used to go through four capillary tubes, and at the ends of the tubes outside the monitored piece the fibers were wound into a bowknot, with the end of it being fitted with an optical fiber clamping to fix the initial size of the bowknot. Meanwhile, the optical fiber should be able to slide freely in the fiber clamping, and the other end should be secured with special glue. The four sides of device were surrounded by optical fibers which were numbered. According to the response speed of the optical fiber of four different positions, the movement directions of rock and soil body were judged. The landslide movement direction was the direction of numbered fiber which had the fastest reaction. Figure 1 shows a schematic diagram of the transducer. Based on our previous studies, the cross-section of the base material, both EPS and PVC, are $40 \times 40 \mathrm{~mm}$ and $1 \#$ optical fiber was only studied in this paper (direction determining of 2\#, 3\#, and 4\# optical fiber has been studied $[14,15])$.

When the COFT is monitoring the landslide, as long as the strength and stiffness of the grouting material are appropriate, the grouting will deform and remain consistent once the surrounding rock or soil mass deforms. Because the anchor end of COFT does not move in the process of shearing, the transducer can be analyzed as a cantilever structure, as shown in Figure 2. The shearing stress of the landslide mass which has a shearing displacement $\left(l_{\mathrm{BE}}\right)$ was detected by COFT, and capillary tube had a retraction displacement $(S)$ due to the low and the bonding strength in the mortar. The curvature radius of the bowknot reduced and caused microbending loss, which will be measured by OTDR. At the same time the displacement of the capillary tube at the sliding plane is composed of three parts, a straight line $(f)$ and two $\operatorname{arcs}(\widehat{h i}$ and $\overparen{\mathrm{km}})$; that is,

$$
S=\widehat{h i}+\widehat{k m}+f \neq l_{\mathrm{BE}}=l .
$$

According to Figure 2 and formula (2), the shearing deformation $(l)$ of sliding mass and the retraction displacement $(S)$ of the tubes are very close but not the same.

\section{Establishment of the Landslide Empirical Formula Based on the COFT}

\subsection{Test of Optical Fiber Bowknot Microbending}

3.1.1. Test Objective. The COFT consists of an optical fiber bowknot and different materials, and they are acting together. The mechanism of monitoring a landslide is as the following: the movement of the slope causes the deformations of the optical fiber and the bowknot and then leads to the microbending loss gathered by OTDR. Therefore, it is essential to set up an empirical formula based on COFT related to the microbending loss and the retraction deformation of optical fiber. 


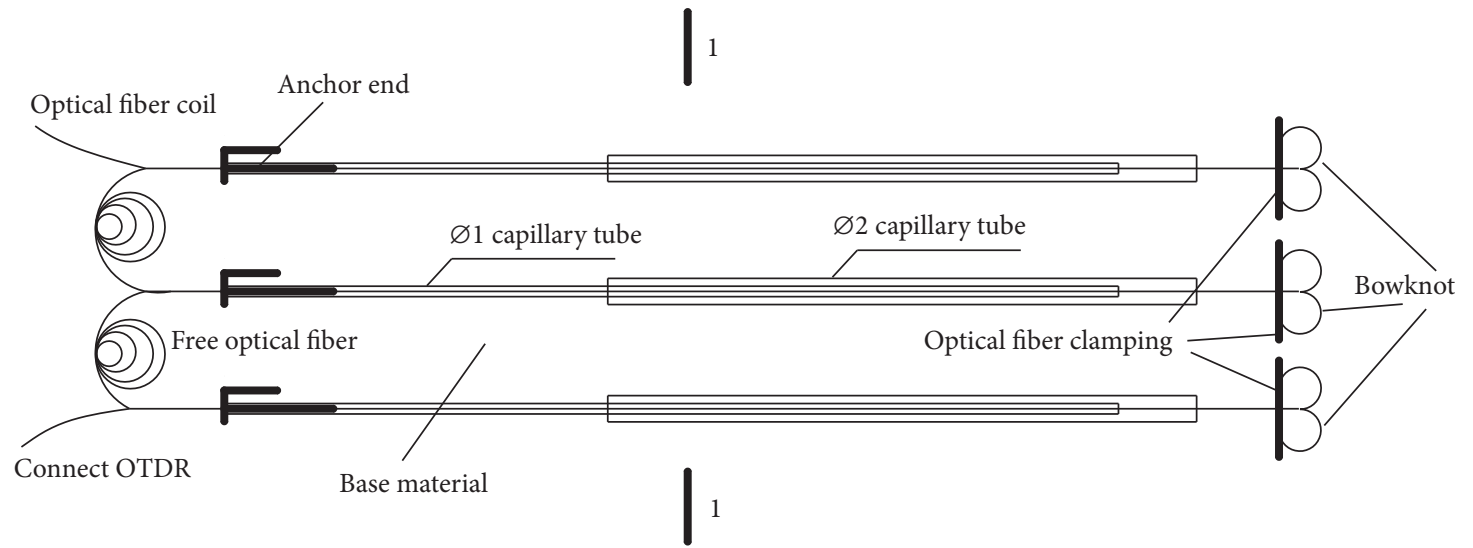

(a) Overhead view of the transducer
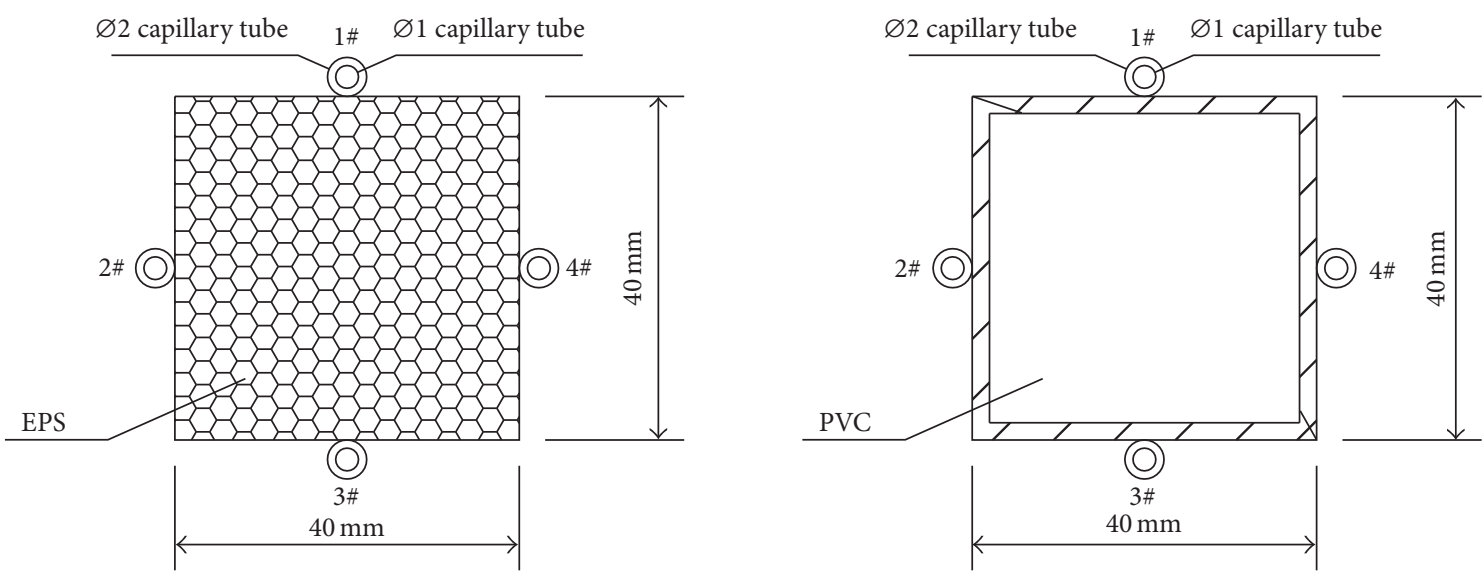

(b) 1-1

FIGURE 1: Diagram of the combined optical fiber transducer (unit: $\mathrm{mm}$ ).

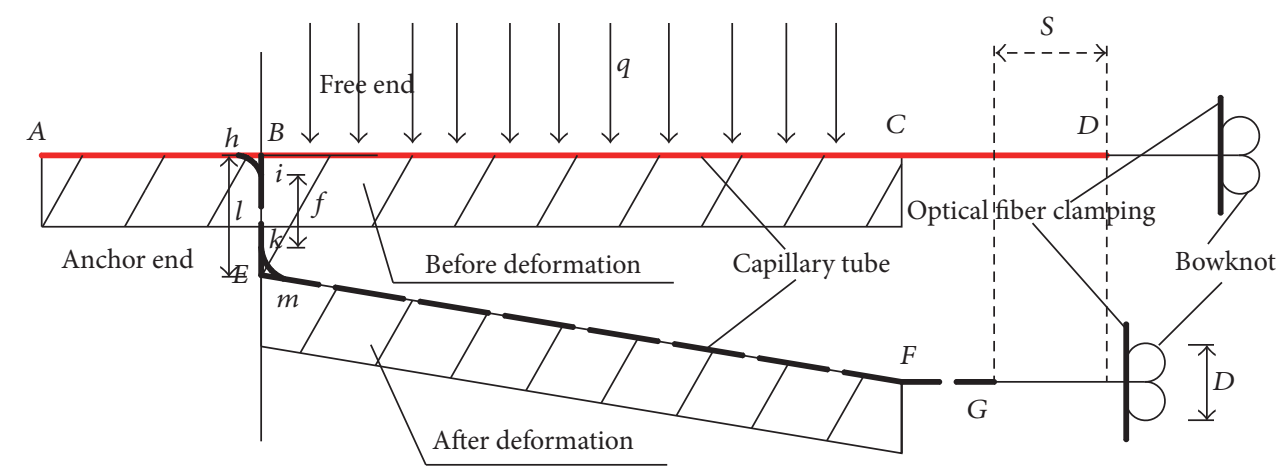

FIGURE 2: Operating mechanism diagram of the COFT (cantilever structure model).

3.1.2. Test Process. Reserve a length of free optical fiber not shorter than $60 \mathrm{~m}$ at one end of a $2 \mathrm{~km}$ reel of optical fiber (simple module, type G652B, Wuhan Yangtze Optical Fiber and Cable Co. Ltd. Wuhan, China). Wind the free optical fiber around a $\Phi 25 \mathrm{~cm}$ pipe and connect it to OTDR (type 6418, manufactured by the 41st Institute of China Electronics Technology Group Corporation, Hefei, China), making a microbending modulation mechanism (bowknot) between the optical fiber disc and the free optical fiber, as shown in Figure 3. Measure the initial $S$ and $D$. To begin the test, increase 
TABLE 1: Parameters of direct shear test.

\begin{tabular}{|c|c|c|c|c|c|c|}
\hline Test group & Model number & $\begin{array}{c}\text { Dimension of } \\
\text { the model } \\
(\mathrm{mm})\end{array}$ & $\begin{array}{l}\text { Material of } \\
\text { transducer }\end{array}$ & $\begin{array}{l}\text { Cross section of } \\
\text { the transducer } \\
(\mathrm{mm})\end{array}$ & Mortar ratio & $\begin{array}{l}\text { Curing time } \\
\text { (day) }\end{array}$ \\
\hline \multirow{2}{*}{1} & $\# 1$ & $500 * \Phi 110$ & PVC & $40 \times 40$ & $1: 4$ & 3 \\
\hline & $\# 2$ & $500 * \Phi 110$ & EPS & $40 \times 40$ & $1: 4$ & 3 \\
\hline \multirow[t]{2}{*}{2} & $\# 3$ & $500 * \Phi 110$ & PVC & $40 \times 40$ & $1: 5$ & 3 \\
\hline & $\# 4$ & $500 * \Phi 110$ & EPS & $40 \times 40$ & $1: 5$ & 3 \\
\hline \multirow{2}{*}{3} & $\# 5$ & $500 * \Phi 110$ & PVC & $40 \times 40$ & $1: 6$ & 3 \\
\hline & $\# 6$ & $500 * \Phi 110$ & EPS & $40 \times 40$ & $1: 6$ & 3 \\
\hline
\end{tabular}

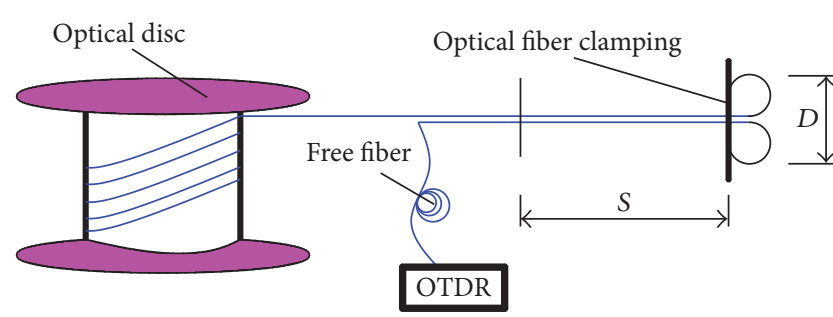

FIgURE 3: Tensile test of optical fiber bowknot structure.

the distance of $S$; the bowknot's width $D$ will decrease correspondingly to generate microbending loss to be collected by OTDR. The tests lasted until the data of the optical fiber loss disappeared.

3.1.3. Test Results and Analysis. The test was conducted eight times, with the initial bowknot width being $40.23 \mathrm{~mm}$, $39.38 \mathrm{~mm}, 38.51 \mathrm{~mm}, 37.48 \mathrm{~mm}, 36.63 \mathrm{~mm}, 35.21 \mathrm{~mm}, 34.56 \mathrm{~mm}$, and $34.1 \mathrm{~mm}$. Figure 4 (a) shows that the curves indicate the relationships between microbending loss and the retraction displacement of optical fiber in the case of different bowknot widths, and Figure 4(b) shows the local zooming-in of $0 \sim 1 \mathrm{db}$ part.

According to Figure 4(a), the curve tendency between microbending loss and the retraction displacement of optical fiber is similar in the cases of different bowknot widths. According to Figure 4(b), when the microbending loss is $0.1 \mathrm{db}$, the smallest displacement of the optical fiber is the curve whose bowknot's initial width $D=34.56 \mathrm{~mm}$, and its corresponding measuring range is relatively large. In slope stability monitoring, the low initial measurement precision is not good for landslide forecasting. Therefore, based on the high initial measurement precision and larger measuring range, the curve whose bowknot's initial width $D=34.56 \mathrm{~mm}$ is the best choice.

Considering choosing such equation as $y=a e^{b x}$, we calculated the parameters of the assumed exponential function and determined the relationship between the microbending loss and the retraction deformation of optical fiber as the following:

$$
\begin{aligned}
y & =a e^{f(x)}-1=e^{0.7116 \ln (x)+1.7842}-1 \\
& =5.954814 x^{0.7116}-1,
\end{aligned}
$$

where $x$ is microbending loss (unit: db). $y$ is the retraction displacement of the optical fiber (unit: $\mathrm{mm}$ ).

\subsection{Verification of Empirical Formula Based on Grouting Direct Shearing Tests}

3.2.1. Test Objective. Formula (3) which states the relationship between microbending loss and the retraction displacement of optical fiber is an empirical formula, but the shearing displacement of landslide mass would not been calculated directly through fiber optic microbend loss by formula (3). When monitoring landslides, the COFT is buried in the boreholes that are grouted with a certain ratio of cement mortar. When a landslide occurs, its damage is similar to the shearing damage of a cantilever beam. Therefore, it is necessary for verifying the reliability of empirical formula to carry out the direct shearing tests with the transducer being buried in the grouting material.

3.2.2. Test Process. A test model was made with a $\Phi 110 \mathrm{~mm}$ PVC pipe that is $500 \mathrm{~mm}$ long. Three groups models were made, the base material were both EPS and PVC, and the ratios of cement mortar were $1: 4,1: 5$, and $1: 6$ so as to compare the influences of different base materials and different proportions of cement mortar on the empirical formula (see Table 1). The shuttering, $\Phi 110 \mathrm{~mm}$ PVC pipes were cut into two half-piece and wrapped with tape for the convenience of shuttering removal. Put the COFTs into the PVC pipes; then cement mortar was grouted into the shuttering too. As shown in Figure 5(a), after three days' curing, the shuttering was removed, and the models were put into the direct shear apparatus one by one. The optical fiber was then put through the samples, which were connected to the OTDR. Before the test, a prepassing test for the optical fiber was conducted. During the test, a hydraulic jack was used for loading. The 


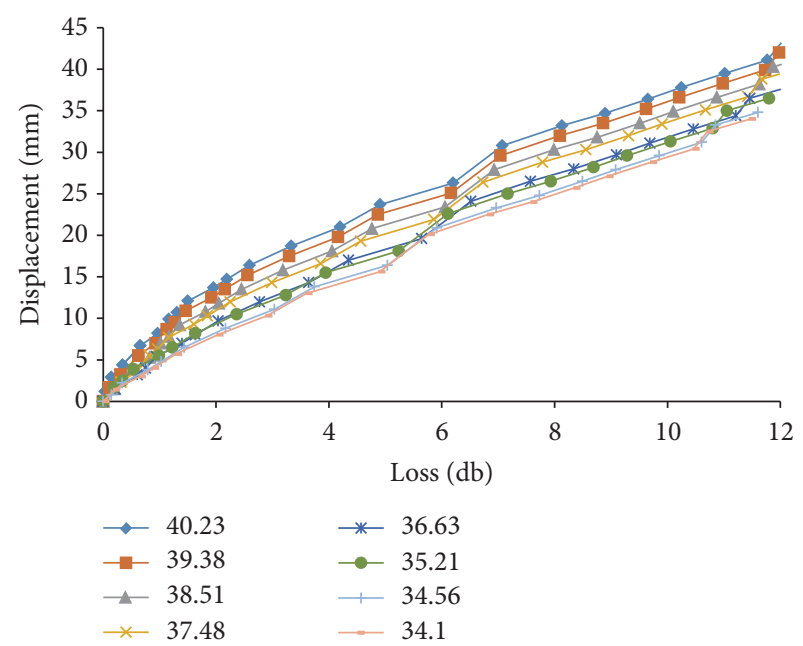

(a) The whole graph

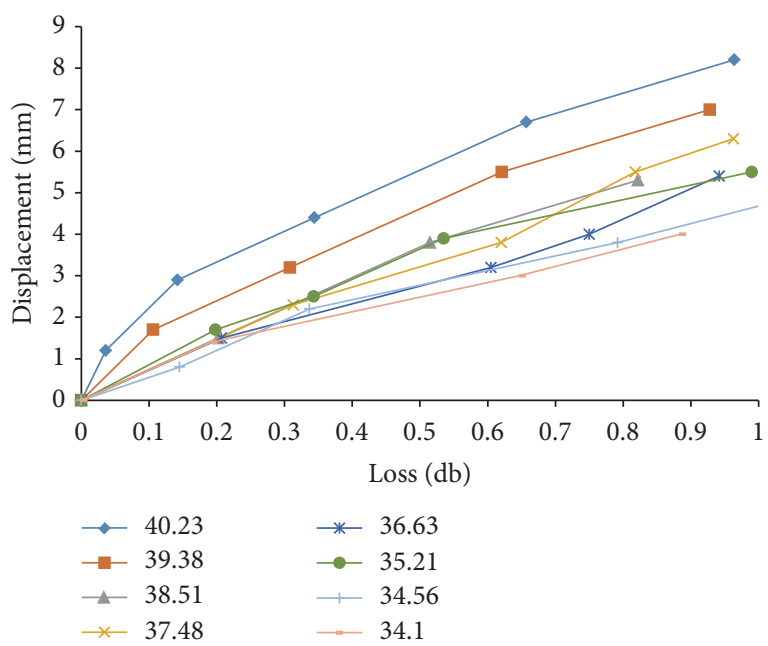

(b) $0 \sim 1 \mathrm{db}$ local zoom

FIGURE 4: The relationship between microbending loss and the retraction displacement of optical fiber in the different initial width of bowknots.

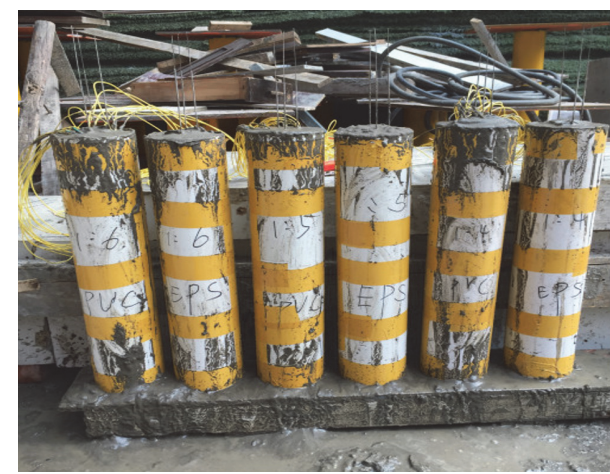

(a) Specimen making

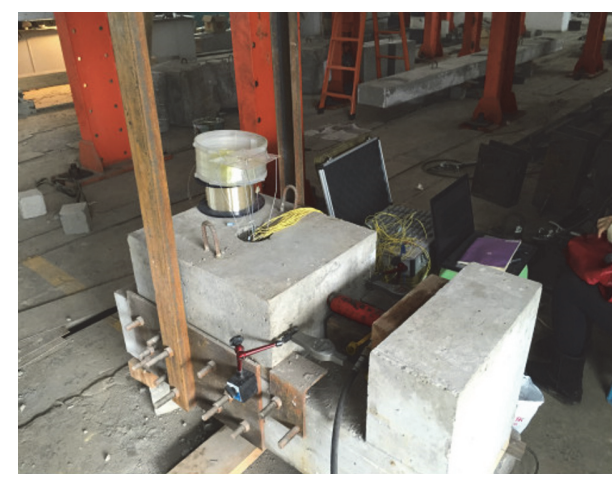

(b) Photo of the shearing tests

FIGURE 5: Direct shear test of grouting piece.

displacements of the upper block were measured by two dial indicators on both sides of the jack. The tests lasted until the signal of optical fiber microbend loss disappeared or the test pieces were seriously damaged. Shown in Figure 5(b), the bow width, optical fiber loss, and shearing sliding distance were recorded.

3.2.3. Test Results and Analysis. Figure 6 shows the relationships between the optical fiber microbending loss and the shearing displacement $(l)$ and the displacement $(S)$ of optical fiber calculated by formula (3).

According to Figure 6 and Table 2,

(1) the trends of the optical fiber sliding distance measured during the test and calculated based on formula (3) are almost the same with each other, which means that the COFT-based landslide empirical formula established as formula (3) is feasible,

(2) the optical fiber sliding distance calculated is about $90 \%-110 \%$ of those measured and the deviations are within the range of sampling errors; therefore, formula (3) can be used well to monitor landslides,

(3) the trends of the curves are largely the same despite the different proportions of the mortar and the different base materials, but the maximum sliding distance of the optical fiber is different. In the three groups, the measured optical fiber sliding distance is the largest when the mortar proportion is $1: 5$. The main reason for this is that, in direct shearing process, the relatively high strength of the test pieces (mortar proportion being 1:4) will lead to the fragility of the capillary tubes in the optical fiber, thus causing no signal in the optical fiber. By contrast, the relatively low strength of test pieces (mortar proportion being 1:6) will lead to the fragility of the test pieces in the shearing process and thus stop the collection of signals. In addition, according to Table 2, the maximum error of the mortar with a proportion of $1: 5$ is lower, both $1: 4$ and $1: 6$. However, regardless of whether the base material is PVC or EPS, the mean square deviation of the errors 


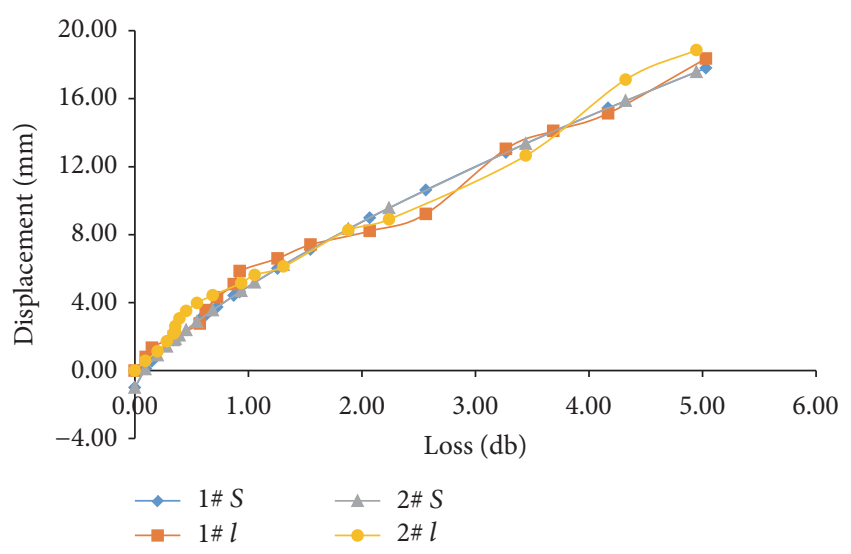

(a) Test model 1

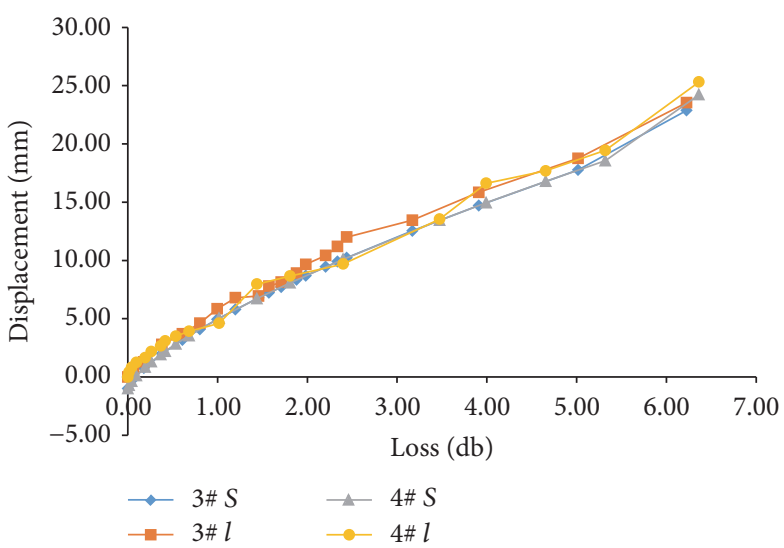

(b) Test model 2

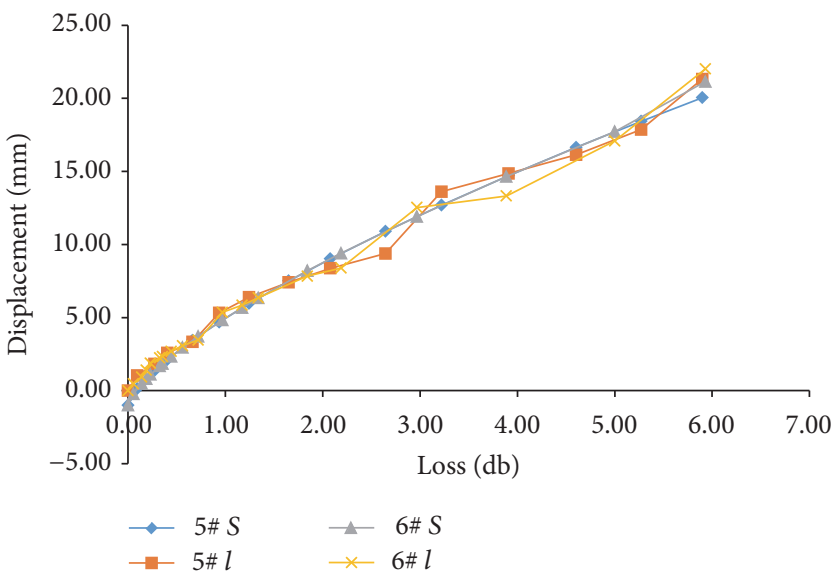

(c) Test model 3

FIGURE 6: The relationships between the shearing displacement $(l)$ of sliding mass, the calculated displacement $(S)$ by formula (3), and microbending loss.

TABLE 2: Error analysis of the measured and calculated displacement by formula (3) of optical fiber.

\begin{tabular}{|c|c|c|c|c|c|c|}
\hline \multirow{3}{*}{ Error } & \multicolumn{6}{|c|}{ Specimen } \\
\hline & \multicolumn{2}{|c|}{$1: 4$} & \multicolumn{2}{|c|}{$1: 5$} & \multicolumn{2}{|c|}{$1: 6$} \\
\hline & PVC & EPS & PVC & EPS & PVC & EPS \\
\hline Maximum (\%) & 21.34 & 28.12 & 14.56 & 10.3 & 17.23 & 22.7 \\
\hline Minimum (\%) & 2.1 & 2.32 & 2.13 & 1.2 & 2.4 & 1.4 \\
\hline Average (\%) & 3.3 & 6.5 & 5.4 & 4.12 & 7.54 & 6.3 \\
\hline Mean square deviation & 10.9 & 7.23 & 6.32 & 5.23 & 9.1 & 7.2 \\
\hline
\end{tabular}

is the minimum, which means that the transducer has the best performance in data collection when the mortar proportion is $1: 5$. Therefore, the proportion of the mortar for grouting is set as 1:5 in the later landslide monitoring.

\section{Model Test of an Artificial Slope}

The feasibility of applying empirical formula based on a COFT to performance monitoring of an artificial slope is investigated in this study. A medium-sized model test at $1 \mathrm{~g}$ condition was conducted in Chongqing University of
Science \& Technology. During testing, two types of COFT were used to measure displacement of sliding surface; an inclinometer monitoring internal movement of the slope mass was compared to COFTs.

4.1. Test Chamber and Model Materials. Figure 7 shows the test chamber used in this study. The length, width, and height of this chamber are $4.5 \mathrm{~m}, 2 \mathrm{~m}$, and $1.6 \mathrm{~m}$, respectively. The lateral walls are made of toughened glass for easy observation of the deformation process and the others are made of thick steel plates. The chamber has a $4 \mathrm{~m}$ long central portion to accommodate the model slope. The friction between the soils 
TABLE 3: Physical and mechanical properties of the test soil and sliding bed.

\begin{tabular}{lccccc}
\hline Name & $\begin{array}{c}\text { Density } \\
\left(\mathrm{kg} \cdot \mathrm{m}^{-3}\right)\end{array}$ & Poisson ratio & $\begin{array}{c}\text { Young's modulus } \\
(\mathrm{Mpa})\end{array}$ & $\begin{array}{c}\text { Cohesion } \\
(\mathrm{Kpa})\end{array}$ & $\begin{array}{c}\text { Friction angle } \\
\left({ }^{\circ}\right)\end{array}$ \\
\hline Sliding bed & 2500 & 0.2 & 11000 & 3470 & 14.4 \\
Sliding mass & 1980 & 0.3 & 48 & 15 & 22 \\
\hline
\end{tabular}

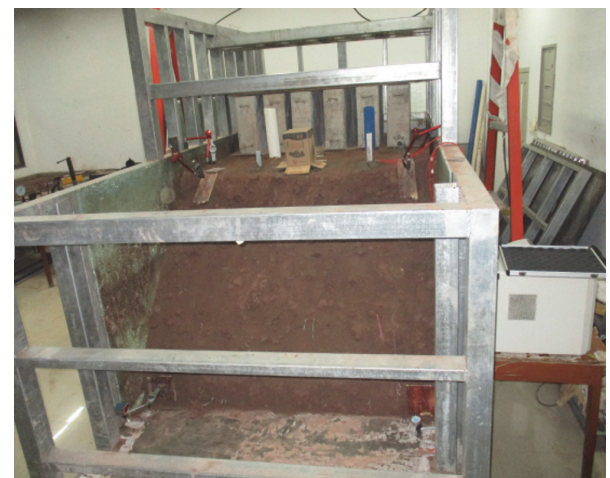

Figure 7: Photograph of the medium-sized test chamber.

and the walls was significantly reduced by applying a thin layer of petroleum grease at the soil-wall. The sliding plane was designed and precast as circular arc. The sliding bed was constructed of MU20 shale bricks and M5 cement mortar and on its surface was plastered with $1: 1$ cement mortar and was covered by a stainless steel plate with a thickness of $1.5 \mathrm{~mm}$ to reduce the friction coefficient. The friction coefficients before and after covering steel plates were 0.63 and 0.27 , respectively.

The soil used in the model test was a mixture of clay and river sand by dry weight. Table 3 presents the physical and mechanical properties of this soil and sliding bed.

4.2. Model Construction and Test Procedure. The dimensions of the artificial model slope are shown in Figure 8. The slope was filled with sandy clay in layers, with a thickness of $20 \mathrm{~cm}$ for each layer. A cutting ring was used for sampling after compaction to measure the basic parameters of the soil sample. The model slope was constructed with a slope inclination of $60^{\circ}(1.73 \mathrm{~V}: 1 \mathrm{H})$. It was $1.6 \mathrm{~m}$ high, which includes a slope height of $1.3 \mathrm{~m}$ and a base height of $0.3 \mathrm{~m}$.

The internal displacements of the slope were monitored by the COFT and inclinometer, with the layout as shown in Figure 9. To guarantee hole-forming, mechanical drilling was conducted below the sliding plane; $\phi 75 \mathrm{~mm}$ (placed PVC COFT and EPS COFT) and $\phi 110 \mathrm{~mm}$ (placed inclinometer) PVC pipes were put into the bore-hole. After the slope was constructed, the COFTs and an Acrylonitrile Butadiene Styrene (ABS) inclinometer pipe were put into the PVC pipes. Cement mortar with a proportion of $1: 5$ was poured under pressure from the bottom of the bore-hole. Pull out the $\phi 75 \mathrm{~mm}$ and $\phi 110 \mathrm{~mm}$ PVC pipes while grouting. The inclinometer pipe was embedded between the two COFTs for comparison monitoring. To make sure that the movement of the slope can cut the COFTs to acquire the monitoring data, a piece of baffle that was $1.7 \mathrm{~m}$ in length, $0.6 \mathrm{~m}$ in width, and $0.01 \mathrm{~m}$ in thickness was placed in the drilled hole.

During testing, the surcharge loading was applied on the slope crest and gradually increased to simulate progressive slope failure. A $20 \mathrm{~mm}$ thick iron plate (1\#) of $2 \mathrm{~m}$ width and $1 \mathrm{~m}$ length was placed on the slope crest beforehand, with twelve $200 \times 520 \times 500 \mathrm{~mm}$ concrete blocks being uniformly placed on the bearing plate. Another bearing plate (2\#) was then placed on the concrete blocks. The loadings of $2.6 \mathrm{kpa}$, $5.2 \mathrm{kpa}, 7.8 \mathrm{kpa}, 8.8 \mathrm{kpa}, 14.69 \mathrm{kpa}, 20.58 \mathrm{kpa}, 26.46 \mathrm{kpa}$, $32.35 \mathrm{kpa}, 38.24 \mathrm{kpa}, 44.13 \mathrm{kpa}, 50.01 \mathrm{kpa}, 55.90 \mathrm{kpa}, 61.79 \mathrm{kpa}$, $67.68 \mathrm{kpa}, 73.56 \mathrm{kpa}, 79.45 \mathrm{kpa}$, and $91.23 \mathrm{kpa}$ were applied on it in stages using three hydraulic jacks. The reaction frame is an H-type steel beam, which was connected to the test chamber by welding.

\subsection{Slope Deformation Analysis of Numerical Modeling. Prior} to the model test, the commercial program FLAC $^{3 \mathrm{D}}$ was used to conduct slope deformation analysis of the test. The model domain was divided into two layers based on the actual situations: the sliding bed (group 1) was constructed with MU20 shale bricks and M5 cement mortar, and the sliding mass (group 2) was made of sandy clay. The parameters of the two layers are shown in Table 2. The model is an elastic-plastic model, and its calculation is conducted based on MohrCoulomb yield criterion. The model is $4.5 \mathrm{~m}$ in length, $2 \mathrm{~m}$ in width, and $1.6 \mathrm{~m}$ in height.

The variations of slope deformation under different surcharge loading during the model test are shown in Figures 10 and 11. The analysis results demonstrate that the slope deformation increase dramatically with the increase of loading magnitude as expected. Slope failure occurs when the sliding force cannot be resisted by the shear stresses along the critical slip surface and the forces mobilized in the COFTs and inclinometer. As shown in Figures 10 and 11, the circular critical slip surface moves towards the slope face when the surcharge loading increases to $50 \sim 60 \mathrm{kpa}$.

4.4. Test Results and Analysis. Figure 12 shows the relationships between the measured displacement (measured by inclinometer), the numerical modeling displacement, and the calculated displacement at the sliding surface by formula (3) and the surcharge loading.

According the Figure 12,

(1) the sliding surface deformations of $C$ among the measured displacement (measured by inclinometer), the numerical modeling displacement, and the calculated 


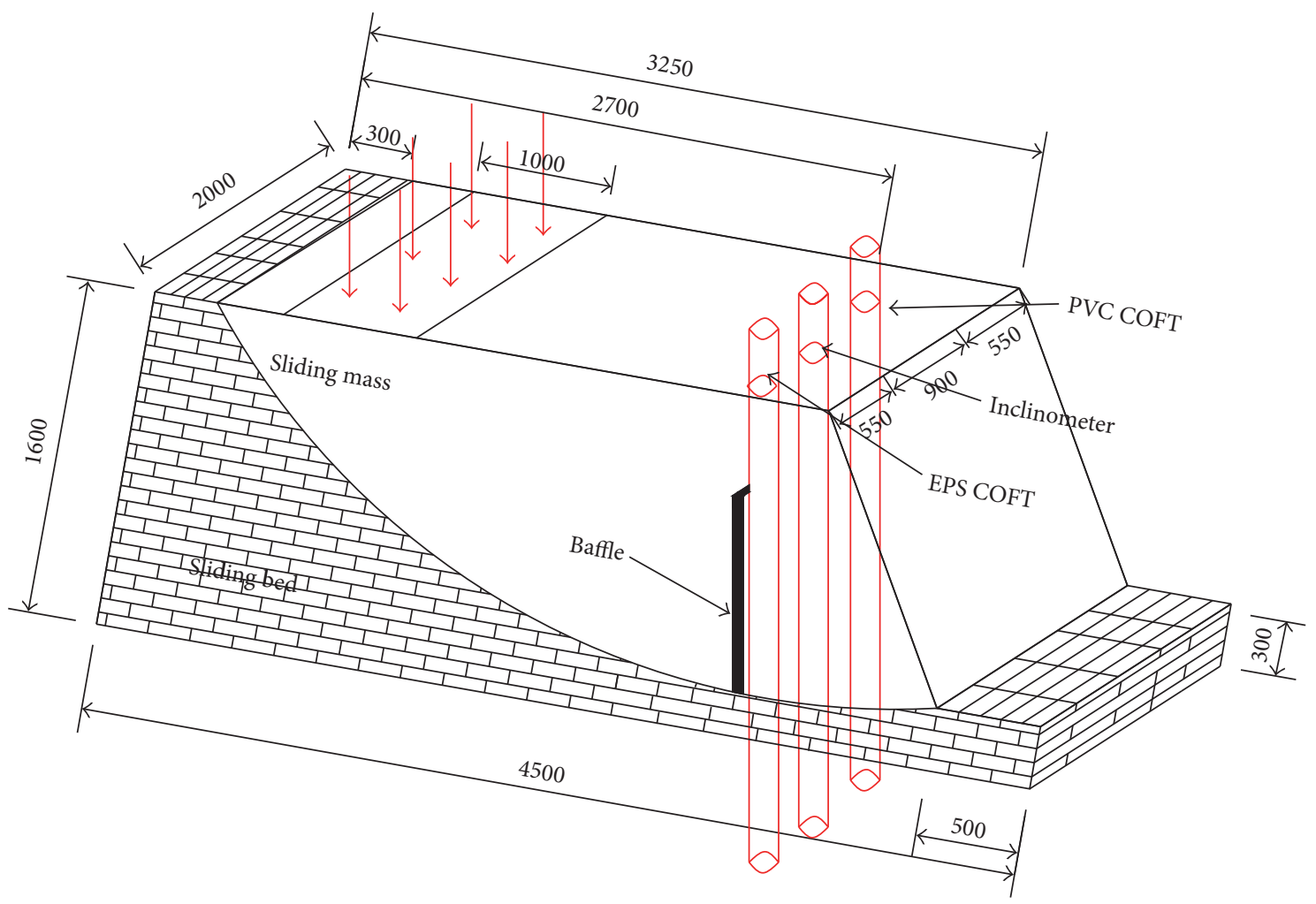

FIGURE 8: Dimensions of the artificial model slope (unit: $\mathrm{mm}$ ).

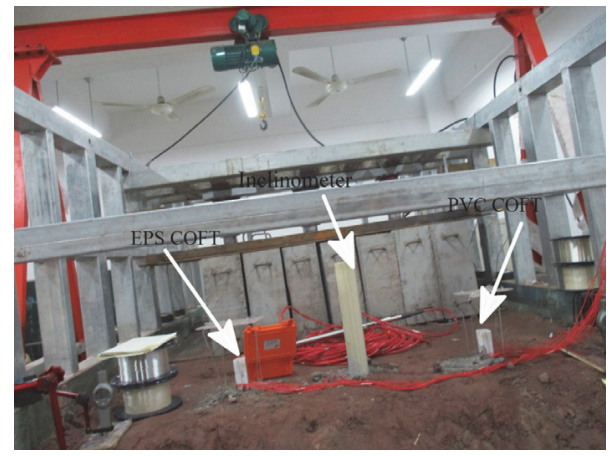

FIGURE 9: Photograph of the installation of COFTs and inclinometer.

displacement at the sliding surface by formula (3) during the model test were developed with increasing loading on the slope crest in an approximately the same curve trend. This indicates the COFT-based landslide monitoring empirical formula is reasonable and reliable,

(2) the measured, the calculated, and the numerical simulation displacement at the sliding surface coincide well. Whether the COFTs with PVC or EPS as the base materials, the forecasting results are in good
TABLE 4: Error analysis of the measured displacement by inclinometer and calculated displacement by formula (3) of $C$ at sliding surface.

\begin{tabular}{lcc}
\hline Material of transducer & PVC & EPS \\
\hline Maximum (\%) & 18 & 15.3 \\
Minimum (\%) & 2.23 & 3.12 \\
Average (\%) & 7.5 & 5.68 \\
Mean square deviation & 4.24 & 3.17 \\
\hline
\end{tabular}

agreement with the test and numerical simulation results. So formula (3) is very reliable.

\section{Discussion}

5.1. About the Base Material of COFT. Error analysis of the measured displacement by inclinometer and calculated displacement from formula (3) at sliding surface of $C$ are shown in Table 4.

According to Table 4, it is found that the maximum error for the EPS is $15.3 \%$, which is lower than $18 \%$ for PVC, while the minimum error is $3.12 \%$, which is higher than $2.23 \%$ for PVC. The mean square deviation is 3.17 and is $33.75 \%$ lower than that of PVC which is 4.24. These indicate that the monitoring performance of transducers with EPS as the base material are better for sandy clay slopes. This is the same as our previous study $[14,15]$. 


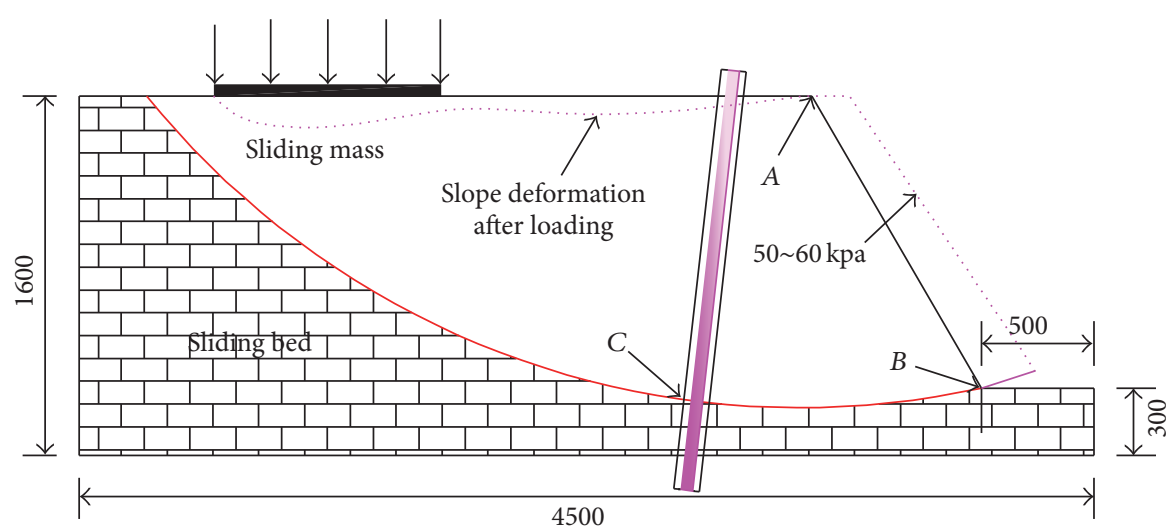

Figure 10: Model slope deformation under different surcharge loading.

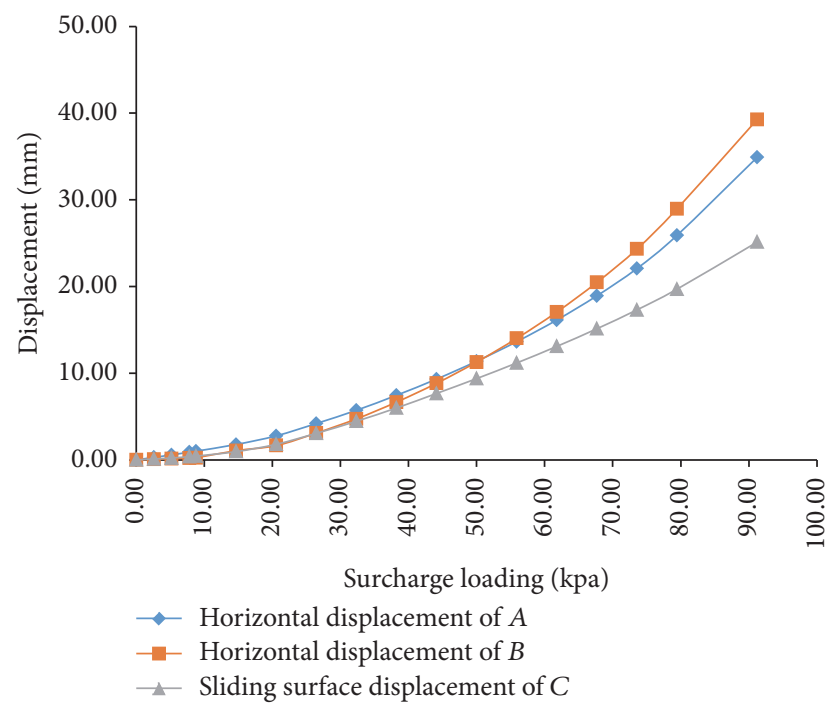

FIgURE 11: Relationship between model slope deformation from numerical modeling and the surcharge loading.

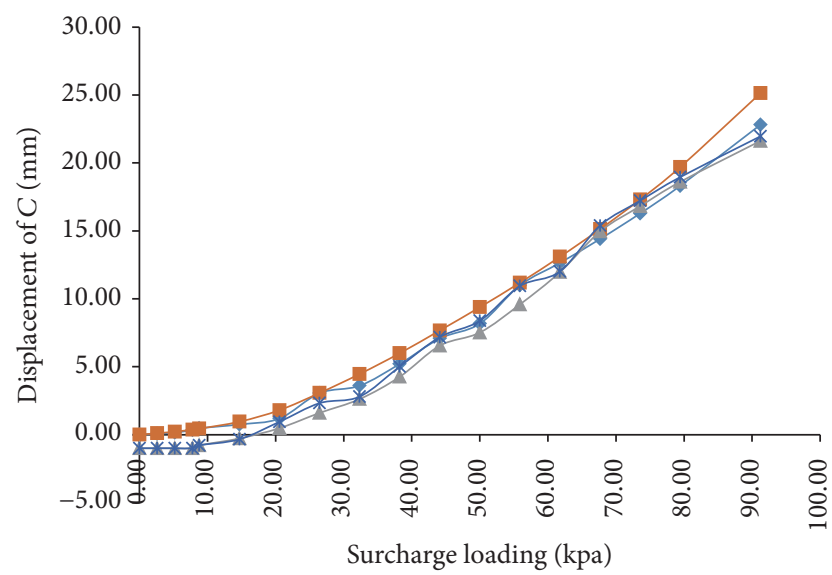

$\rightarrow$ Measured by inclinometer $\quad \longrightarrow$ Calculated (PVC)

$\rightarrow$ Numerical modeling displacement $\quad$ * Calculated (EPS)

FIGURE 12: Relationships between measured displacement, numerical modeling displacement, and the calculated displacement by formula (3) of $C$ at the sliding surface and the surcharge loading.
5.2. Comparison of This Method with Other Methods. The COFT is used for landslides monitoring; hence the transducer should have the advantages of a higher initial measurement accuracy, a larger dynamic range, a low price, remote and real-time monitoring, and the ability to determine the movement direction of landslides. Therefore, we compare the method in this paper with other bore-hole based monitoring methods shown in Table 5 .

As shown in Table 5,

(1) comparing with other bore-hole based monitoring methods, the initial measurement accuracy of our method is $1 \mathrm{~mm}$. Although this is higher than single fiber, it is far lower than TDR,

(2) the dynamic range of our method is greater than $26.5 \mathrm{~mm}$ higher than other methods,

(3) as to the device cost price, our method costs only $\$ 0.2 / \mathrm{m}$, which is slightly higher than that of single optical fiber, but far lower than TDR.

Therefore, COFT has a larger dynamic range, higher resolution, and minimal initial measurement accuracy. And the device has the characteristics of the simple structure, low cost, easy installation, and the ability to determine the movement direction of landslides.

5.3. Actual Application Conditions on the Sensor. The installation location of the sensor designed by us is very important; both of the calibration experiment and the model experiment are carried out on the obvious slip surface, but in the field monitoring, our sensors will be applied well if there is a weak interlayer in the rock slopes or slope has a more obvious slip surface. Whereas if it is not easy to determine the slip surface, there will be some limitations on this sensor. The distributed optical fiber sensing technology can effectively monitor the slope body strain and displacement information. Taking the BOTDR technology widely applied currently as an example, its measurement range of the optical fiber strain is about $1.5 \%$. Therefore, its measurement range is relatively small and the installation is also more difficult. In practical application, our sensors can be considered to be combined 
TABLE 5: Comparison of this method with other methods.

\begin{tabular}{|c|c|c|c|c|c|c|c|}
\hline \multirow[b]{2}{*}{ Testing method } & \multicolumn{2}{|c|}{ Precision of initial measurement } & \multicolumn{2}{|c|}{ Max sliding distance } & \multirow{2}{*}{$\begin{array}{l}\text { Dynamic range } \\
(\mathrm{mm})\end{array}$} & \multirow{2}{*}{$\begin{array}{l}\text { Determination of the } \\
\text { loading direction }\end{array}$} & \multirow{2}{*}{$\begin{array}{l}\text { Unit price } \\
\text { (USD/m) }\end{array}$} \\
\hline & Value $(\mathrm{mm})$ & $\begin{array}{l}\text { Reflectometry } \\
\text { Correlation/loss }\end{array}$ & $\begin{array}{l}\text { Value } \\
(\mathrm{mm})\end{array}$ & $\begin{array}{l}\text { Reflectometry } \\
\text { Correlation/loss }\end{array}$ & & & \\
\hline TDR [4] & 5.0 & $0.005(\rho)$ & 25.4 & $0.123(\rho)$ & $0-20.4$ & Can not & 13.5 \\
\hline Single fiber [17] & 0.3 & $0.5(\mathrm{~dB})$ & 3.60 & $54(\mathrm{~dB})$ & $0-3.3$ & Can not & 0.03 \\
\hline COFT $[14,15]$ & 1 & $0.11(\mathrm{~dB})$ & 26.5 & $9.1(\mathrm{~dB})$ & $0-23.2$ & Can & 0.2 \\
\hline
\end{tabular}

with other distributed optical fiber technologies to carry out the combined measurement on the overall information of the slope, which is also the direction that our team has been trying to explore.

\section{Conclusion}

This paper analyzes the fundamental principles of a COFTbased method for landslides monitoring. The stretching test of optical fiber bowknot, COFT grouting direct shearing tests, and a large-scale landslide model test are carried out. Numerical modeling verification with FLAC $^{3 \mathrm{D}}$ is also conducted and comes to the following conclusions:

(1) The empirical formula based on COFT is established and has been verified by the indoor experiment and numerical modeling, and this means that the COFTbased empirical formula is suitable for the future field application.

(2) When the ratio of cement mortar is $1: 5$, the error between the calculated value by the empirical formula and the measured value is the smallest. The monitoring performance of transducers with EPS as the base material is better for sandy clay slopes.

(3) The results of the comprehensive analysis of the method used in this paper and other methods show that the method in this paper has the advantages of higher initial measurement precision, a larger measuring range, a real-time feature, low price, and the ability to determine the movement direction. The COFT has obvious advantages for landslide monitoring and is more practical for field work.

\section{Conflicts of Interest}

The authors declare that they have no conflicts of interest.

\section{Acknowledgments}

Projects 51178488 and 51478066 are supported by National Natural Science Foundation of China. The authors thank greatly Associate Professor Bao-yun Zhao, Tong-qing Wu, and $\mathrm{Zi}$-yun $\mathrm{Li}$ from the School of Civil Engineering and Architecture, Chongqing University of Science \& Technology, and Peng Liu and Zhen-yang Feng from the School of Civil Engineering of Chongqing University for their help during the experiment.

\section{References}

[1] China Geological Environment Information Network, Geological Hazards Investigation and Monitoring Room of China Geological Environmental Monitoring Institute [EB/OL], 2015, http:// www.cigem.gov.cn.

[2] K. J. Tsai, S. H. Yu, C. P. Hsiao, M. C. Ho, and C. C. Chen, "Investigations by using GPS/GIS/RS technology on the slope stability of Kaohsiung communities on slope land in Taiwan," in ISOPE2005: Proceedings of the Fifteenth International Offshore and Offshore and Polar Engineering Conference, vol. 1-4, 2005.

[3] S. M. Sargand, L. Sargent, and S. Farrington, Inclinometer-Time Domain Reflectometry Comparative Study: Final Report, Ohio Research Institute for Transportation and the Environment, Ohio University, 2004.

[4] N. D. Dennis, C. W. Ooi, and V. H. Wong, "Estimating movement of shallow slope failures using time domain reflectometry," in Proceedings of the TDR Conference, Paper ID 41, 16 pages, Purdue University, West Lafayette, Ind, USA, September 2006, https://engineering.purdue.edu/TDR/Papers/41_Paper.pdf.

[5] H.-F. Pei, J.-H. Yin, H.-H. Zhu, C.-Y. Hong, W. Jin, and D.-S. Xu, "Monitoring of lateral displacements of a slope using a series of special fibre Bragg grating-based in-place inclinometers," Measurement Science and Technology, vol. 23, no. 2, Article ID 025007, 2012.

[6] Y. L. Wang, B. Shi, T. L. Zhang, H. H. Zhu, Q. Jie, and Q. Sun, "Introduction to an FBG-based inclinometer and its application to landslide monitoring," Journal of Civil Structural Health Monitoring, vol. 5, no. 5, pp. 645-653, 2015.

[7] C.-Y. Hong, Y.-F. Zhang, M.-X. Zhang, L. M. G. Leung, and L.-Q. Liu, "Application of FBG sensors for geotechnical health monitoring, a review of sensor design, implementation methods and packaging techniques," Sensors and Actuators A: Physical, vol. 244, pp. 184-197, 2016.

[8] L. Zeni, L. Picarelli, B. Avolio et al., "Brillouin optical timedomain analysis for geotechnical monitoring," Journal of Rock Mechanics and Geotechnical Engineering, vol. 7, no. 4, pp. 458462, 2015.

[9] M. Iten and A. M. Puzrin, "BOTDA road-embedded strain sensing system for landslide boundary localization," in Smart Sensor Phenomena, Technology, Networks, and Systems 2009, Proceedings of SPIE, San Diego, Calif, USA, March 2009.

[10] L.-X. Zhang, Y.-Z. Liu, Z.-H. Ou, Z.-Y. Dai, and C. Zhou, "Research on rock body thrust monitoring system," Opto-Electronic Engineering, vol. 33, no. 7, pp. 52-56, 2006.

[11] I. B. Kwon, C. Y. Kim, D. C. Seo, and H. C. Hwang, "Multiplexed fiber optic OTDR sensors for monitoring of soil sliding," in Proceedings of the 18th Imeko World Congress Metrology for a Sustainable Development, Rio de Janeiro, Brazil, September 2006, http://www.imeko.org/publications/wc-2006/PWC2006-TC20-002u.pdf. 
[12] K. Higuchi, K. Fujisawa, K. Asai, A. Pasuto, and G. Marcato, "Application of new landslide monitoring technique using optical fiber sensor at Takisaka Landslide," in Proceedings of the 1st North American Landslide Conference, pp. 1074-1083, Vail, Colo, USA, June 2007.

[13] Z. W. Zhu, Q. Y. Yuan, D. Y. Liu et al., "Composite optical fiber device and detection module," China Patent: CN201010107782.02011.

[14] Z.-W. Zhu, Q.-Y. Yuan, D.-Y. Liu, B. Liu, J.-C. Liu, and H. Luo, "New improvement of the combined optical fiber transducer for landslide monitoring," Natural Hazards and Earth System Sciences, vol. 14, no. 8, pp. 2079-2088, 2014.

[15] Z.-W. Zhu, D.-Y. Liu, Q.-Y. Yuan, B. Liu, and J.-C. Liu, "A novel distributed optic fiber transduser for landslides monitoring," Optics and Lasers in Engineering, vol. 49, no. 7, pp. 1019-1024, 2011.

[16] H.-W. Liu, Y.-H. Wu, R. Ding, and L. Wen, "Nonlinear finite element analysis and tests of fiber-optic strain sensing," Journal of Optoelectronics Laser, vol. 14, no. 5, pp. 526-528, 2003 (Chinese).

[17] T. Tian Guo, W. Qing Yuan, and L. Hao Wu, "Experimental research on distributed fiber sensor for sliding damage monitoring," Optics and Lasers in Engineering, vol. 47, no. 1, pp. 156-160, 2009. 


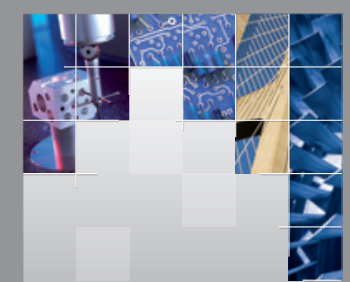

\section{Enfincering}
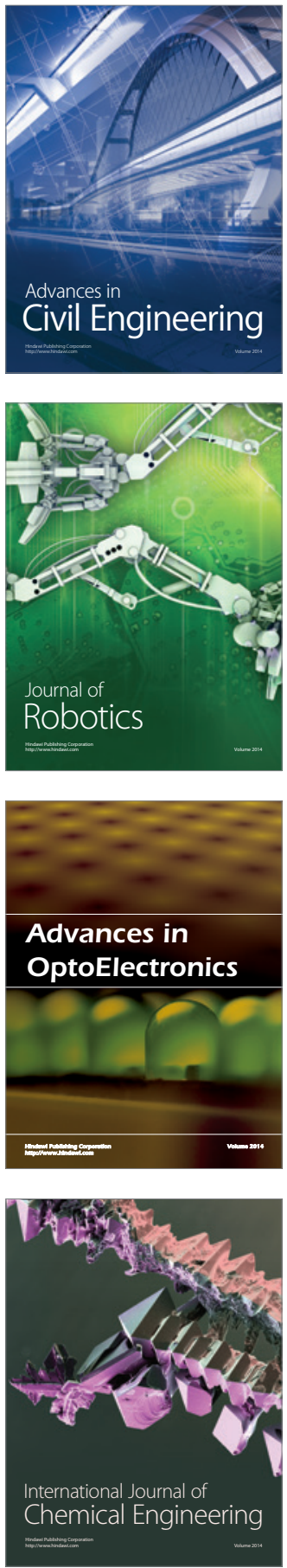

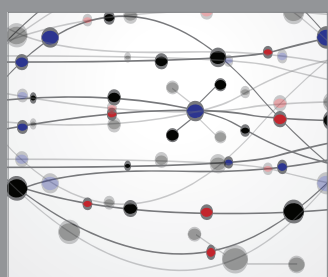

The Scientific World Journal

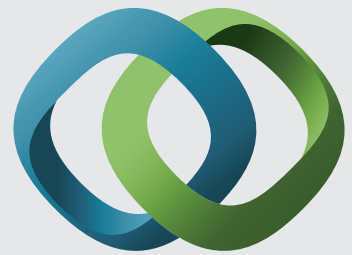

\section{Hindawi}

Submit your manuscripts at

https://www.hindawi.com
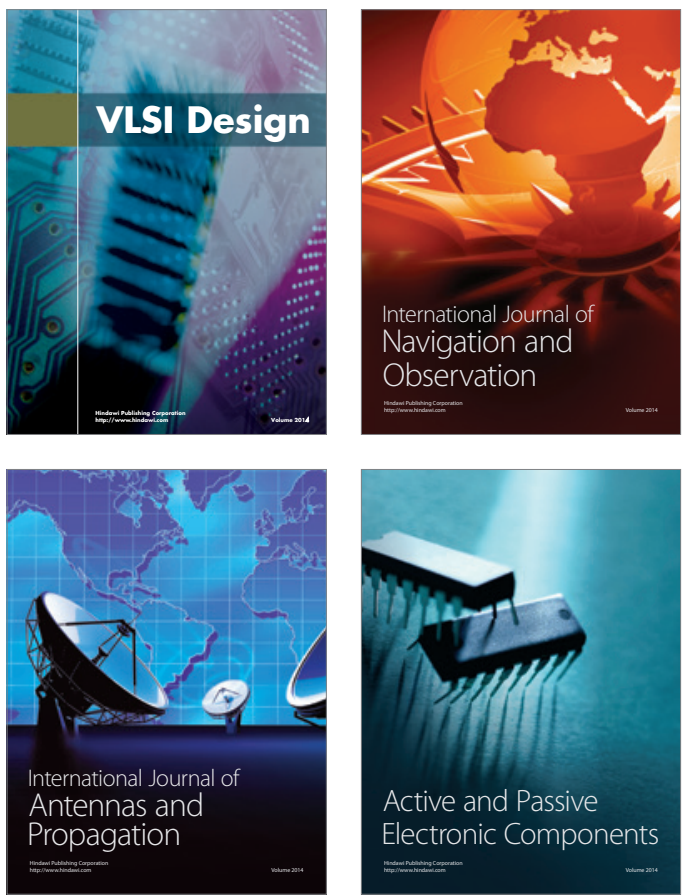
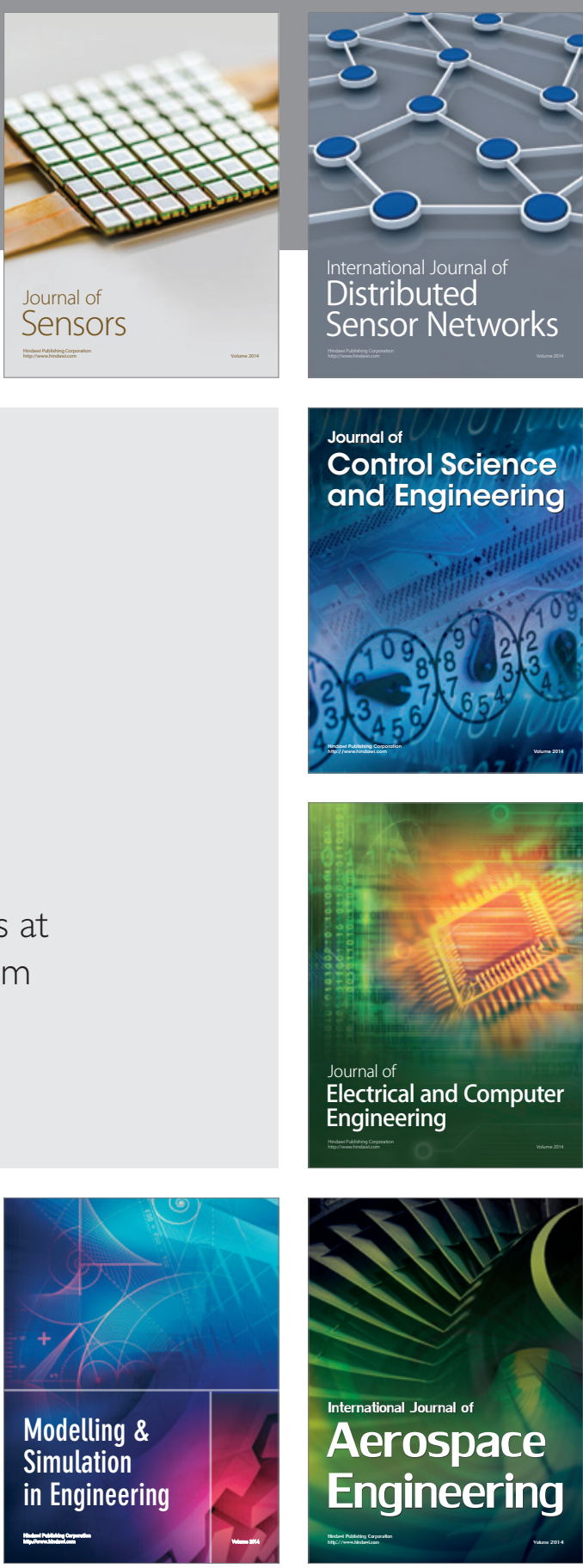

International Journal of

Distributed

Sensor Networks

$-$

Joumal of

Control Science

and Engineering
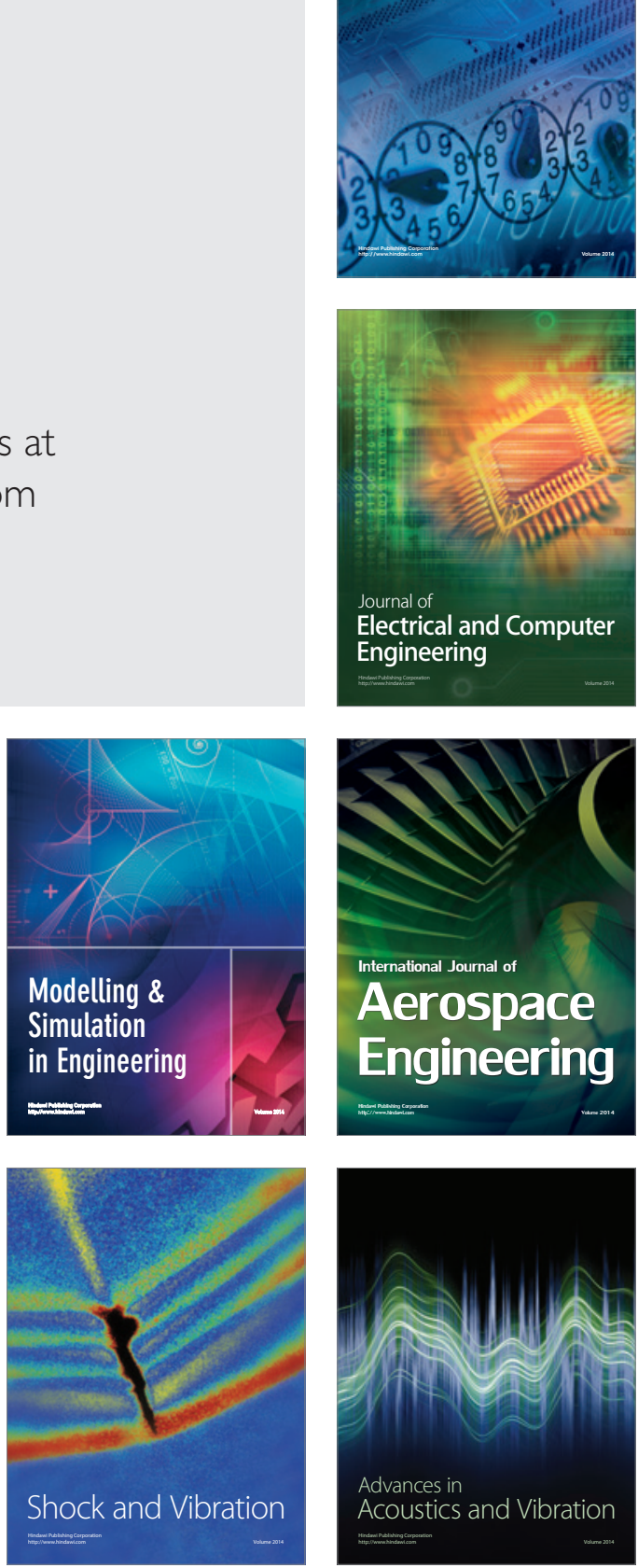